\title{
EL RECONOCIMIENTO ÉTICO DE LAS VÍCTIMAS DE LA VIOLENCIA DEL MERCADO
}

\author{
XABIER ETXEBERRIA \\ Universidad de Deusto
}

\begin{abstract}
RESUMEN: En este estudio se afronta el reto de aplicar a las víctimas de los mercados la categoría filosófica de reconocimiento. Metodológicamente, se presentan las diversas dimensiones de este y se proyectan a continuación en las víctimas: el sufrimiento injusto como expresión del mal reconocimiento, el esquema del reconocimiento y su realización victimadora en el mercado, la relevancia de la dimensión institucional y de la identidad en el espacio mercantil victimador, las luchas por el reconocimiento de/con las víctimas y su horizonte de justicia.
\end{abstract}

PALABRAS CLAVE: víctimas, reconocimiento, mercado, instituciones, identidad.

\section{Ethical recognition of the victims of market violence}

\begin{abstract}
This study takes on the challenge of applying the concept of philosophical recognition to the victims of market violence. The author discusses several dimensions of recognition, which are then projected onto the victims: Unfair suffering as an expression of misrecognition, the scheme of recognition and the victims that are generated when applied by the markets, the relevance of the institutional dimension and of identity in the victimizing market space, the struggle for recognition of/ with the victims, and its perspective of justice.
\end{abstract}

KEY WORDS: victims, recognition, market, institutions, identity.

\section{SobRE EL OBJETIVO DE ESTE ESTUDIO Y SUS REFERENCIAS BÁSICAS}

Ya en 1969, Galtung propuso una concepción amplia de violencia injusta - y por tanto, de víctimas en sentido moral- distinguiendo entre violencia directa, que implica relaciones interhumanas destructivas expresas, y violencia estructural, en la que la destrucción se encuentra en el funcionamiento objetivo de las instituciones, especialmente las económicas. En la primera, el sujeto violentador y su víctima aparecen manifiestamente. En la segunda, si bien puede detectarse a la víctima ${ }^{1}$, los victimarios, que debe haberlos para que se trate de víctima moral, son difícilmente identificables, quedan difuminados.

Pues bien, los sujetos que esta reflexión tendrá presentes van a ser las víctimas de las estructuras económicas. Dado que estas toman forma en instituciones, resulta útil asumir una distinción entre estas que nos ofrece Renault (2004b). Algunas, dice, se muestran simples dispositivos de coordinación de la acción; otras definen además espacios específicos, con precisas reglas técnicas

1 GaLtung (1985) la define como la persona que tiene desarrollos reales de sus posibilidades humanas manifiestamente inferiores a los desarrollos potenciales socialmente posibles, por ejemplo, aquella a quien se le acorta fuertemente la duración de su vida por problemas de subalimentación grave evitable o de falta de acceso a medicinas existentes. 
de acción y de interacción, propuesta de normas y configuración de expectativas, constituyéndose en lugares de socialización y de generación de identidad. Por lo que se refiere al ámbito económico, el primer tipo de instituciones está expresado hoy por el mercado; mientras que el paradigma del segundo tipo es la empresa, incluyendo en ella no solo la que produce bienes y ofrece servicios, sino también la financiera. Dado que las empresas siguen dominantemente las pautas del mercado, será esta institución difusa la que se tendrá aquí como referencia primaria para las víctimas que se van a contemplar: las generadas por el mercado.

Así delimitado el sujeto abordado, queda por definir el tipo de acercamiento a él. Pretende ser ético-político. Si tomamos como referencia la sociedad industrial, pueden señalarse tres grandes propuestas o guías para la lectura crítica de la realidad y la acción transformadora con las que afrontar las injusticias sufridas en el ámbito de la producción económica y el acceso a sus bienes, provocadas por su misma estructuración.

La primera es la que en sentido amplio podemos denominar marxiana. Cabe destacar de ella para los propósitos de estas líneas: su conexión expresa con las experiencias de explotación, de las que se nutre y a las que vuelve; su visión de la realidad en clave de conflictividad y lucha entre quienes tienen intereses opuestos y se configuran como clases sociales; su referencia, clave para la justicia, de transformación de la concepción y el disfrute de la propiedad, para poner en el centro la propiedad colectiva, pretendiendo hacer así viable el principio «a cada uno según sus necesidades, de cada uno según sus posibilidades»; su dilución de la experiencia de identidad de la víctima, al sobreponer a ella la identidad del revolucionario transformador y al dirigir decisivamente la mirada al futuro, tendiendo a instrumentalizar las referencias vivenciales al pasado de sufrimiento. No es aventurado afirmar que, en buena medida, ha sido este soslayamiento en la consideración de la víctima moral en cuanto tal, que es la que lleva a la acogida de toda víctima, lo que ha facilitado las derivas gravísimamente victimadoras que se han dado en las realizaciones estatales comunistas que han pretendido inspirarse y justificarse en este modo de afrontar la injusticia económica, vista como corazón de toda injusticia.

La segunda propuesta es la de las teorías procedimentales del liberalismo político igualitario, de las que es emblemática la de Rawls. Destaco de ella estos rasgos: las referencias a las realidades de injusticia, esto es, a las víctimas, quedan en sordina, en el sentido de que la teoría se sostiene al margen de que existan o $\mathrm{no}^{2}$; la lógica interna que conduce a la formulación de principios e incluso al señalamiento de reglas para su puesta en práctica es la del consenso, amparando debates discursivos pero no tomando como referencia de base las luchas sociales; la categoría clave para la justicia es la de la distribución imparcial y equitativa de los bienes primarios, incluyendo una distribución desigual solo en la medida en que se precisa para garantizar la equidad con los

2 Se presupone la existencia de desaventajados, pero en cuanto tales no son víctimas. 
desaventajados; en el sustrato de todo está la aportación kantiana del reconocimiento de toda persona como libre e igual, que, como tal, previene enfoques victimizadores pero abstractamente. Orientando esta propuesta a nuestro tema, lo que puede ser fortaleza dialéctica en ella —su orientación procedimentalista, su puesta entre paréntesis para el proceso reflexivo de las realidades sociales vivas-, es a la vez su punto débil, el que desvela importantes lagunas en ella al confrontarla con las experiencias de victimación —aquí, ligadas a la economía-, ya sea por las injusticias ante las condiciones de desventaja, ya sea por otras formas de opresión y marginación.

La tercera propuesta, aunque hundiendo sus raíces próximas en Hegel, es de factura más contemporánea. Me refiero a las teorías que ponen el reconocimiento en el centro del acercamiento a la justicia. Comparten con la primera postura su basamento en la injusticia existente, interpretada ahora como mal reconocimiento; pero añaden un matiz importante: se trata de reconocimiento ante el sufrimiento injusto padecido, esto es, se trata del sufrimiento que constituye a la víctima como tal. En segundo lugar, vuelven también al agonismo, ahora en forma de luchas por el reconocimiento. En tercer lugar, varían entre ellas, entre otras cosas, a causa del mal reconocimiento que atienden prioritariamente: fue Taylor (1997) quien planteó con fuerza la categoría para aplicarla a la diferencia identitaria cultural; Honneth, en polémica con Taylor, resaltará su proyección a la «experiencia de humillación y menosprecio» (Honneth, 2010: 10) en cuanto no reconocimiento de la dignidad de los individuos; y será por último Renault - por citar únicamente a tres autores emblemáticos-el que con sus énfasis en la conexión entre instituciones y reconocimiento, mejor situará la categoría para afrontar nuestro objetivo del mal reconocimiento en los mercados (Renault, 2004b y 2007). En cuarto lugar, todos asumen, aunque con aplicaciones diferentes, que reconocer es identificar, esto es, que reconocimiento e identidad van de la mano.

Pues bien, aquí me propongo: acercarme a la víctima de los mercados a partir de la categoría de reconocimiento, remitiendo a ella, con la necesaria articulación y discernimiento, aportaciones de diversos autores; hacerlo no meramente resaltando el basamento en el sufrimiento que causa el mal reconocimiento, sino subrayando el protagonismo del sujeto víctima en las luchas de reconocimiento; y consiguiendo así que el abanico completo de la temporalidad tenga más relevancia, al incorporar el pasado al espacio de la justicia.

2. El SUFRIMIENTO INJUSTO CAUSADO POR EL MERCADO COMO LUGAR DE NEGACIÓN Y DE RECLAMACIÓN DE RECONOCIMIENTO

1. En el enfoque de justicia que estoy considerando el arranque está, pues, en las experiencias de daño, de sufrimiento, que son interpretadas como negaciones del reconocimiento debido, y percibidas en consecuencia como "heridas 
morales». Deben distinguirse, por eso, de los sufrimientos identificables como desgracias que nos ocurren sin que, directa o indirectamente, hayan intervenido otros humanos para causárnoslas ${ }^{3}$.

Esto introduce una dimensión psicológica en las dinámicas de reconocimiento. En palabras de Honneth (1966: 10): «La experiencia de una injusticia moral debe ir siempre acompañada de una conmoción psíquica, en cuanto que el sujeto sería víctima de una decepción de una expectativa cuya realización pertenece a las condiciones de su identidad propia». Más de uno recela de esta introducción del sentimiento en la definición de lo injusto, por lo que tiene de particular y de riesgo de irracionalidad. Personalmente, estoy con Renault (2004) cuando resalta todo su valor, no solo motivacional, sino incluso cognitivo desde el punto de vista moral, al implicar en la frustración ante la situación vivida los principios que la califican como injusta y al alentar una dinámica práctica que persigue transformarla de acuerdo a ellos. La imparcialidad de la justicia no puede ser confundida con la neutralidad afectiva, sino que reclama, para hacerse viva, afectividad purificada que se ensamble con la racionalidad.

De todos modos, a la justicia le interesa la afectividad que tiene contexto e impacto público. Por eso, el propio Renault habla de «sufrimiento social», en el que anida el sufrimiento psíquico pero: abriendo a la universalidad de lo que nos debemos unos a otros; y emergiendo de negaciones de reconocimiento que están socialmente instituidas. El daño lo vive la persona, como fragilización, relación negativa o destrucción de la relación consigo mismo, pero enmarcado en contextos sociales que la desbordan.

En una descripción así de la frustración de las expectativas de reconocimiento late una ineludible carga normativa: se tiene la pretensión de que la vivencia del daño, que se entiende responde a un daño objetivo, es de tal naturaleza que revela un derecho, precisamente en su negación. Y dado que este daño es el mal reconocimiento, la dimensión normativa y lo que implica pasan a ser contempladas como reconocimiento debido.

Se produce de este modo una articulación de perspectivas que da a la categoría de reconocimiento toda su fuerza ético-política para expresar la justicia. Por un lado, está una situación particular injusta de mal reconocimiento, que aporta su densidad de realidad; por otro, hay una vivencia sentimental aguda de la situación, que es ella misma revelación de injusticia y motivación para la acción transformadora; por último está la dimensión normativa de un derecho reclamable que hace aparecer el universal en lo concreto, con su correspondiente validación, haciendo político en sentido propio lo que desde el momento sentimental y las protestas ligadas a él (piénsese en el fenómeno de «los indignados») podría mostrarse como prepolítico, si relacionamos esto con políticas concretas.

3 Aunque ante ellos, tendremos derecho a reclamar una solidaridad que, si no acontece, pasa a hacer de la desgracia una herida moral. Ante una catástrofe «natural» hay que preguntarse: ¿ha habido causas humanas que han incidido en los daños que ha acarreado?, ¿ha habido insolidaridades posteriores que han sostenido o acrecentado los daños? 
Las consideraciones precedentes presuponen que quien sufre objetivamente la injusticia vive el correspondiente sentimiento de injusticia. Renault advierte con razón que la injusticia sufrida no produce per se sentimiento de injusticia, que la injusticia más trágica ocurre cuando se da lo primero pero no lo segundo: cuando la opresión ha impactado tan fuertemente en la conciencia de identidad de la víctima que esta queda, por mecanismos de interiorización, a merced del opresor, bloqueándose toda lucha. La negación de reconocimiento se da aquí a la segunda potencia, al no reconocerse los efectos de la ausencia de reconocimiento (piénsese, para nuestro tema, en quien sufre solo vergüenza por no tener trabajo, al autoatribuirse totalmente la responsabilidad). Renault postula para estos casos que el filósofo se constituya, no en el representante de quienes no vivencian la injusticia, pero sí en su portavoz, en el sentido de productor del discurso que se precisa para transformar la sociedad que genera estas víctimas mudas. La propuesta convoca oportunamente al pensamiento solidario, pero los esfuerzos primeros y más relevantes deben adquirir la forma de acompañamiento a/con la víctima para que su autonomía lúcida y capaz se refuerce. Renault habla de ofrecerle cuadros cognitivos que le faciliten vivir y formular por ella misma como injustos los reconocimientos negativos.

Ante este enmarque de las dinámicas de reconocimiento en hechos de injusticia vivenciados como tales se impone una alerta crítica. Porque si bien toda injusticia vivida es sufrimiento, no todo sufrimiento es injusticia. El empresario que sufre porque le obligan a pagar una cuantiosa multa debido a que defraudó gravemente a Hacienda, no es víctima, no sufre mal reconocimiento. Siempre habrá que preguntarse ante un sufrimiento con causas sociales si hay responsabilidad moral en agentes o instituciones de la sociedad, porque únicamente en caso afirmativo estamos ante una injusticia.

2. Para aplicar el enfoque del reconocimiento a las víctimas del mercado, tenemos que acercarnos, pues, de arranque, al sufrimiento que este causa, a cómo es vivido y a si puede ser considerado injusto. Dentro de dicho enfoque, Honneth, actualizando a Hegel, habla (1996, con Fraser 2003: 113-120) de tres esferas para el reconocimiento en el orden que subyace al capitalismo: a) la del amor o intimidad o cuidado, en la que nos mostramos como personas con necesidades y en la que la referencia es la (auto)confianza; b) la jurídica, en la que somos individuos iguales en derechos y obligaciones, en autonomía, cuya referencia es el (auto)respeto jurídico, sustentado en el valor igual de todos en el espacio público jurídico-político; c) la de la economía o el logro en la estructura de la división del trabajo, en la que la pretensión es mostrarnos con talentos valiosos para la sociedad, en la que la lucha por el reconocimiento se muestra lucha por la distribución, con el referente de la (auto)estima social. El autor entra en la discusión, confrontándose con Taylor, de si habría que postular una cuarta esfera de la identidad cultural colectiva, algo que rechaza, creo, demasiado expeditivamente. Sin abrir aquí este debate, teniendo presentes las tres esferas resulta claro que lo que estoy postulando como victimación del mercado se sitúa en la tercera. 
Para Honneth, si en la tercera esfera se configura la lucha por la distribución como lucha por el reconocimiento del trabajo que cada uno hace en cuanto actividad socialmente necesaria y valiosa, que merece los correspondientes bienes materiales, lo decisivo se juega en el mercado laboral. Es, en definitiva, la esfera del trabajo. El paro estructural es, en este sentido, la negación radical de reconocimiento social, porque deja a quien lo sufre fuera de la experiencia de cooperación. Me gustaría añadir que hay que interpretarlo expresamente como victimación que tiene como consecuencia una grave precariedad revictimadora en la relación con los otros ámbitos del mercado (financiero, de bienes y servicios...). A su vez, no debe desdeñarse que el arranque del sufrimiento injusto venga por otra vía, como la financiera, por ejemplo, con el desplome imprevisto de los ahorros (piénsese en las preferentes en España o en el corralito argentino), que amenaza igualmente la estima de sí con consecuencias prácticas durísimas.

Fraser recela de esta reconducción de todo el ámbito económico a un orden de reconocimiento, además con bases psicológicas, porque teme que diluya un orden de mercado "cuasi objetivo, anónimo, impersonal, que sigue su propia lógica» (Fraser, 2003: 160). El que los mercados estén siempre incluidos en la cultura, advierte, no debe llevar a la conclusión de que su comportamiento está completamente gobernado por la dinámica de reconocimiento. Sin entrar en los considerandos que hace dentro de su esquema reflexivo, creo que hay que prestar atención a esta advertencia, aunque teniendo presente que, precisamente, una perspectiva del reconocimiento profundizada puede aportar nuevas iluminaciones sobre el problema.

Duranty aprecia en principio el enfoque honnethiano, valorando de él la cercanía de la perspectiva normativa y transformadora de la sociedad con las experiencias de injusticia descritas como heridas morales; y entendiendo que «la ética del reconocimiento no es otra cosa que una teoría de los movimientos sociales, la justificación normativa y práctica de las luchas contra la injusticia» (Duranty, 2005: 170). Pero, desde la sensibilidad post-marxista critica la tendencia a reducir la interacción, en concreto en la esfera del trabajo, a relaciones interpersonales, la práctica ausencia de las relaciones con la naturaleza y con los productos del trabajo, esenciales para la autoestima del trabajador, así como la dilución de las mediaciones institucionales, coincidiendo en esta crítica con Renault. Habrá que resaltar más adelante la relevancia de esto último, que da consistencia al paradigma del reconocimiento como referencia para la justicia.

\section{EXPERIENCIAS CONCRETAS DE MAL RECONOCIMIENTO VICTIMADOR DE LOS MERCADOS}

Con las consideraciones precedentes nos hemos introducido ya en las injusticias del mercado. Pero para ser fieles al proceso propuesto en la teoría del reconocimiento de enraizarnos en la experiencia, resulta oportuno poner algunos 
casos concretos que sirvan de referencia para las consideraciones que siguen. Advierto que, al describirlos, suprimo toda mención a violencias, engaños y corrupciones que acrecientan sus efectos negativos, para que se perciba desnuda la violencia de la estructura misma de los mercados.

Piénsese, en primer lugar, en la violencia ligada a la dinámica internacional que rige los precios de los alimentos. Un alza de los mismos impacta de lleno en el gravísimo problema del hambre. Estos son los hechos de partida: en el planeta viven unos 7.000 millones de personas; hay capacidad sobrada de producción agrícola para que puedan alimentarse adecuadamente todas ellas; pero un número elevadísimo - endémicamente, al menos 900 millonespadece hambre y una de cada seis está en riesgo de padecerla; el que suba o baje este número depende en una medida importante de la fluctuación de los precios de los alimentos básicos (como maíz, trigo, arroz, soja). Pues bien, periódicamente, se incrementan de forma desmesurada y con ello, también la hambruna, sobre todo en África y en algunos países de Asia. Fue especialmente dramático el año 2008, pero también se han dado subidas relevantes en el 2012. ¿Cuáles son las causas? Los expertos indican: condiciones climáticas adversas que dañan las cosechas, políticas «irracionales» de producción de agrocombustibles que merman gravemente la producción de alimentos, desidia en el apoyo a pequeños agricultores locales, concentración mundial de la producción y su control en pocas manos (más del $80 \%$ de las exportaciones de cereales provienen de cinco países y están contraladas por cuatro grandes compañías). Todo lo cual da alta volatilidad a los precios de los alimentos básicos, que quedan fuertemente sujetos a la especulación inherente a las dinámicas de mercado a las que están sometidos ${ }^{4}$. En síntesis: la alimentación básica de millones de personas en condiciones sociales muy vulnerables, depende de las fluctuaciones mercantiles ante las que son impotentes y de las que son víctimas.

Un segundo ejemplo lo tenemos en el efecto victimador de las políticas de austeridad en Europa tras la crisis iniciada en 2007-2008, que recuerda en aspectos clave las políticas de ajuste estructural de las décadas de los 80 y 90 aplicadas en América Latina, África Subsahariana y Este de Asia. Según Oxfam Internacional, si las medidas de austeridad tomadas en la UE siguen adelante, en 2025, entre 15 y 25 millones de europeos se sumarán a los ya 120 millones existentes de pobres. Esto es, que caigan en la pobreza, en general a través de su masiva caída en el paro o en el empleo muy precario, depende del mantenimiento de ellas. Entre tales medidas pueden citarse: fiscalidad regresiva, reducción del gasto público en sanidad, educación y servicios sociales, «flexibilización» y precarización del mercado laboral, costosísimos rescates de las instituciones financieras privadas que se traducen en aumento enorme de la deuda pública. Medidas, por cierto, que sí estimulan que los más ricos acrecienten significativamente su participación en el total de ingresos, afianzándose

4 Recuérdese que, incluso, los especuladores pueden decidir artificialmente los precios a través de la bolsa de granos de Chicago. 
la brecha de la desigualdad. En síntesis: «las políticas de austeridad han perjudicado especialmente a las personas más pobres y vulnerables [las ha victimado], sobre quienes se ha hecho caer la responsabilidad de cargar con los excesos de las últimas décadas, a pesar de ser las menos culpables de ellos» (Oxfam, 2013: 3).

\section{ESQUEMAS DEL RECONOCIMIENTO Y SU APLICACIÓN AL ÁMBITO DEL MERCADO}

Con casos como estos de trasfondo en esta reflexión, paso a aplicar a lo que ellos ejemplifican -la generación de víctimas por los mercados- la categoría de reconocimiento. Para lo cual es conveniente hacerse cargo de todo lo que implica.

1. Un modo fundamental pero parcial de acercamiento al reconocimiento es el de Kant: pide que nos reconozcamos unos a otros como sujetos de dignidad. Podríamos considerarlo como reconocimiento especular de las individualidades: yo, sujeto de dignidad, te reconozco a ti en cuanto otro como yo. Hegel se aleja de este enfoque que, entiende, se despega de la realidad. En su etapa joven consagrada en Fenomenología del espíritu, la que más influencia va a tener, plantea el reconocimiento en el marco de la reciprocidad agónica (el paradigma del amo y el esclavo). Supone que toda relación de reconocimiento implica una relación de poder; que esta tiende a plasmarse en relación de dominio; lo que no impide que sea también relación de inter-dependencia entre conciencias, en cuanto que es el reconocimiento del otro el que instaura mi identidad (en el paradigma, de amo o esclavo) en modos que pueden ser opresores; que en una relación de reconocimiento así anida la lucha por el reconocimiento al que se aspira, confrontada con el que se tiene en la dependencia, entrando en la paradoja de que tengo que superar al otro para que no me reduzca a objeto suyo, pero a su vez conservarlo, para que me reconozca sujeto de la relación. Habiendo en todo ello un complejo juego de reflexividad e intersubjetividad en las conciencias ${ }^{5}$.

En este esquema hegeliano tenemos, pues, en su forma manifiesta y en doble dirección, el movimiento reconocer/ser reconocido. Pero hay que sacar a la luz dos implícitos: el de la reflexividad que se autorreconoce incluyendo tensionalmente el reconocimiento del otro; y el de la identidad que reconocemos, en nosotros y en el otro, en movimientos imbricados de atribución y de recepción, que tienen connotación valorativa. Con lo que el esquema completo se expresaría de este modo: a) reconocer/reconocerse/ser reconocido; b) reconocer a alguien, incluido a sí mismo, en tanto que algo.

Los actuales pensadores reconducen, en general, la dinámica hegeliana hacia el reconocimiento recíproco no destructivo e incluso mutuamente creativo

5 Para ampliar estas referencias véase: Hegel (2009), Pierini (2009), Maza (2009). 
como horizonte al que, salvando positivamente la densidad de la reflexividad y la intersubjetividad, la lucha tiene que apuntar. Puede discutirse en qué medida encuentran apoyo en Hegel. Sin entrar aquí en este tema, me permito señalar un dato útil para nuestros propósitos. El Hegel maduro (ver Jaeschke, 2009) considera que la lucha por el reconocimiento es algo propio del estado de naturaleza, importante, porque funda la sociedad, pero transitorio, porque decae cuando el Estado de derecho, «en el que cada uno es reconocido por sí mismo y por los otros», se consolida.

2. Apliquemos este esquema de reconocimiento a las víctimas de los mercados. Ya Hegel tenía un planteamiento sugerente sobre estos, el trabajo moderno y el dinero regulador: son universales porque lo abarcan todo, pero abstractos; y contagian de este rasgo al individuo que participa en ellos: lo reconocen como sujeto libre, pero abstracto también. Podría decirse que en la esencia del mercado late una lógica impersonal, que fragiliza la consistencia del reconocimiento porque diluye la consistencia de la identidad en el ser empresario o trabajador o consumidor o inversor o especulador...: identidad de fondo común definida por la orientación a la exterioridad y con variaciones individuales medidas por el éxito en esta exteriorización. El problema está en que en sociedades como la nuestra, la dimensión de los mercados es tan potente que tiende a invadir las otras dimensiones y a configurarlas a su medida.

Por más que, en la teoría, la esfera de la producción sea también la esfera de la cooperación social, los mercados hoy funcionantes adquieren, por su propia constitución, esto es, más allá de que medien violencias directas, engaños y corrupciones - que evidentemente, los hay-, tales autorregulaciones objetivas desbordantes de la autonomía de las personas, tales orientaciones a lucros privados, que se desentienden del bien público, tales propensiones a grandes concentraciones de riqueza, que sumergen a la mayoría en la pobreza y la precariedad, obscenamente contrapuestas a la opulencia de la minoría. Pero entremos en detalles, aplicando a estos mercados el esquema del reconocimiento.

Partamos del momento básico «reconocer activo / ser reconocido pasivo». El sujeto reconocedor activo inicial puede mostrársele, por ejemplo a un trabajador de una empresa, el empresario; o en un banco a su cliente, el responsable de darnos un crédito. Pero en la medida en que ellos están englobados en «los mercados» y sometidos a su lógica, son estos mercados los que acaban funcionando como auténticos sujetos, abstractos pero muy eficaces. Puede decirse que se nos revelan bajo la metáfora del «amo». Nos reconocen como aquellos que debemos someternos a sus dinamismos, que tenemos que medir nuestra consistencia por el éxito y nuestro valer por el valer para el mercado, etc. De modo tal que si no llegamos ni siquiera a los mínimos, si estamos expulsados de su rueda, simplemente no existimos; en este caso su mal reconocimiento adquiere la forma de invisibilización.

Ahora bien, del nosotros «ser reconocidos» así, pasivamente, emerge activamente, en dialéctica, un reconocerlos a ellos. Puede ser a la manera de una identidad — soy en efecto, sobre todo, eso que se me asigna—, que muestra un 
reconocer a los mercados como lo que pretenden ser, con lo que su dominación está justificada, pues fuera de ellos «no hay salvación». El objetivo es, entonces, quedar bien situado en ellos, pero, incluso cuando me marginen, será por mi culpa, y mi preocupación será reinsertarme sin ponerlos en cuestión. En este reconocimiento de los mercados tiende a darse una «naturalización» de ellos: aunque son creación muy humana, contingente, convencional, se han consolidado de tal modo que parece que son así porque así está en la «naturaleza de las cosas» que sean. Este reconocimiento es el que más consolida al amo. Formalmente no hay víctimas, pues lo que sucede a los oprimidos y marginados por los mercados entra en el orden de lo que es y no puede ser de otra manera. Se trata de desgracias, de daños colaterales inevitables.

Ahora bien, el reconocer que el reconocido por los mercados devuelve a estos, puede ser de otra naturaleza, si lo inscribe en la conciencia de mal reconocimiento sufrido y en la lucha por enmendarlo. Ya no interpreta el sufrimiento que causan como desgracia, porque no cree en esa naturalización, sino como injusticia; no sitúa al victimado en la lógica de daños colaterales sino en la del chivo expiatorio que es sacrificado; discierne y asume las responsabilidades que pudiera tener en el estado de cosas, pero localizando y denunciando las responsabilidades decisivas de quienes acumulan poder en las grandes corporaciones y los ámbitos de decisión políticos y económicos, esto es, personalizando la impersonalización de las estructuras en los grandes sostenedores de estas.

Hay que ser conscientes de que la tarea es difícil. Porque las víctimas invisibilizadas, marginadas, vulnerables, tienen complicada la organización de su resistencia. Porque se enfrentan a estructuras como tales despersonalizadas y a sostenedores de ellas que pueden aducir no haber quebrantado la normatividad social, parapetados en ellas con frecuencia anónimamente, con los que es impensable imaginar relaciones intersubjetivas, a los que es jurídicamente inviable demandar. Las dificultades se acrecientan por la realidad de unos mercados globalizados. Si Hegel decía que en el Estado de derecho la lucha por el reconocimiento no tendría que existir porque este ya se ha logrado, lo que vemos es que la globalización del mercado, por un lado, consagra el estado de naturaleza a nivel internacional (Jaeschke, 2009) y, por otro, hace retroceder hacia ese estado a los Estados con un reconocimiento cívico importante. Habrá que detenerse luego en lo que está llamada a ser esta lucha, pero de momento hay que dejar constancia de que, como mínimo, se precisa una dinámica reconocer/ser reconocido que no afiance el dominio de los mercados. Y eso debe hacerse reclamando la condición de víctima moral de quienes son maltratados por ellos, hasta puntos extremos — no es desgraciadamente demagogia - de morir de hambre o mientras se está en la lista de espera de un hospital público.

Aunque en esta aplicación del esquema del reconocimiento a los mercados he comenzado por el par básico reconocer/ser reconocido, al desarrollarlo han ido apareciendo los otros elementos que le dan complejidad: que está también el reconocerse, y que en el reconocer, a sí mismo y al otro, hay un reconocer 
algo pero también un reconocer una identidad. Este tema de la identidad, por su relevancia, deberá ser retomado luego.

La aplicación ha sido genérica, a los mercados. Gana en concreción si se proyecta a casos concretos como los que presenté antes. No tengo espacio para hacerlo aquí, por lo que dejo la tarea al lector. Pero creo que, por un lado, es claro que en ellos aparecen las dinámicas aquí apuntadas, y, por otro, que estas se muestran de formas diferenciadas, debido a sus contextos diferentes. Son contextos específicos los que hacen que, en el caso de las crisis alimentarias, la vulnerabilidad de las víctimas y su correspondiente victimación sea mucho mayor; en concreto, su alejamiento geográfico, político y económico de las corporaciones y de los grandes responsables de ellas, a lo que hay que añadir su desperdigamiento geográfico en diversos Estados con estructuras muy frágiles - para colmo, con frecuencia, altamente corruptas- y sin poder en el concierto internacional ${ }^{6}$.

\section{LA INSTITUCIONALIZACIÓN DEL (MAL) RECONOCIMIENTO EN LOS MERCADOS}

En el apartado precedente he jugado con la ambigüedad de considerar a los mercados como sujeto del reconocimiento o como soporte de él. Para clarificarla, se impone afrontar la dimensión institucional.

1. Ya adelanté que se ha criticado a Honneth por su enfoque individualista (recela de las subjetividades identitarias grupales) e intersubjetivista del reconocimiento, lo que pondría en sordina su dimensión institucional. A decir verdad, él la señala, considerando a las instituciones como encarnación de formas específicas de reconocimiento sedimentado (Honneth, 2006). De todos modos, es Renault $(2004,2004 b, 2007)$ el que subraya con fuerza que, en un enfoque de justicia que pretenda alcance político, el acercamiento que debe privilegiarse para identificar los efectos del mal reconocimiento es el institucional. Además, en su sentido fuerte: el que considera las instituciones no expresivas de unas relaciones de reconocimiento dadas — con resolución feliz o frustrada-, de algún modo pre-institucionales, sino constitutivas de ellas, en el sentido de que las producen, a ellas y a sus efectos. Esta producción de efectos de reconocimiento se debe a que las instituciones encarnan esquemas, con carga valorativa, en forma de reglas, normas e identidades (Renault, 2007, 2004b).

- Las reglas de interacción, implicando atribuciones de roles y calificaciones de acciones, producen efectos de reconocimiento al incidir en la valoración de los individuos. En su expresión negativa puede ser denominado reconocimiento menospreciador. Puede adquirir tres formas:

6 En cuanto a la crisis en Europa, frente al manido argumento de la inevitabilidad de la política de duros recortes sociales, véase lo que proponen, centrados en España: NAvARro, TORRES Y GARZÓN (2012). 
devaluación, o reconocimiento del individuo como inferior; descalificación o reconocimiento de que no cumple los criterios de interacción social, lo que provoca la exclusión (ej. que a un inmigrante se le impida entrar en un club); y estigmatización, o reconocimiento como agente de acciones nocivas.

- Las normas a las que habría que ajustar las conductas generan negaciones de reconocimiento que en su conjunto pueden ser calificadas de mal reconocimiento (misrecognition), no tanto del individuo como de su identificación social. Se expresan también de tres formas: reconocimiento inadecuado, en el que se empuja a asumir roles con los que no hay autoidentificación; invisibilidad del colectivo implicado, por ejemplo de las mujeres; supervisibilidad, o identificación total de la persona con el rasgo destacado del colectivo al que pertenece (no ser persona que es negra, sino ser negro).

- Las instituciones, a través de la socialización que implican, constituyen componentes importantes de nuestras identidades personales, que inciden en el reconocimiento. Su expresión negativa puede denominarse reconocimiento insatisfactorio. Adquiere dos formas: reconocimiento inestable (como el del trabajador en el actual capitalismo flexible) y separador de subjetividades, que dificulta identificaciones firmes (como lo que puede pasarle al hijo de inmigrantes confrontado con su diferente y contrapuesta socialización familiar y escolar).

2. Al aplicar este enfoque institucional del reconocimiento a los mercados conviene observar que, según Renault, en su sentido fuerte, se realiza en instituciones que se expresan como espacios sociales específicos (un hospital, una escuela, una empresa productiva o de servicios, un banco...), tanto en sus unidades menores como en el sistema que las engloba. Ahora bien, los mercados son considerados instituciones «tenues» en el sentido de que solo contemplan dispositivos de coordinación de la acción, bien es cierto que enormemente expansivos al impregnar un número muy elevado de instituciones densas. ${ }^{7}$ ¿Cómo concretar en ellos las negaciones de reconocimiento productoras de víctimas?

Conviene advertir de arranque que esta «informalidad» $\mathrm{y}$ «difusividad» de los mercados no puede despistarnos respecto a su impacto. Caillé subraya oportunamente (2004: 27) que hoy las socializaciones secundarias, con sus reconocimientos, están triunfando sobre la socialidad primaria clásica. Y quienes las producen, quienes son nuestros grandes maestros para lo bueno y lo malo, son el Estado, los medios de comunicación... y los mercados.

El impacto de estos en el reconocimiento tiene una vía doble: directamente, interiorizando en nosotros los elementos formales básicos que los componen (competitividad, emprendimiento, productividad, éxito monetario como

7 En conexión con esto léase el texto de Alonso (2013), en donde distingue entre poder duro, el militar, blando, el cultural, y medio, el económico. 
criterio evaluador, etc.), con sus correspondientes valoraciones y orientaciones al reconocimiento; y mediatamente, a través de la incidencia en nuestras vidas del conjunto de instituciones densas en las que participamos o que sufrimos y en las que la lógica del mercado es preponderante (no solo las estrictamente económicas).

Con estos previos, puede tomarse el esquema de Renault de los tres mecanismos institucionales antes señalados, con sus géneros de negación de reconocimiento y sus subgéneros (ocho en total) y detectarlos tanto en nuestras interiorizaciones de la lógica del mercado como en lo que nos acontece a través de las instituciones que la privilegian. Veremos cómo y dónde aparece la devaluación, la descalificación, la estigmatización, la inadecuación, la invisibilidad, la supervisibilidad, la inestabilidad y la separación de identidad.

Remitiéndonos en concreto a los casos antes expuestos, veremos cómo en las hambrunas mediadas por los mercados, la negación de reconocimiento de las víctimas adquiere en especial la forma de invisibilización, pero estando subliminalmente debajo de ella la devaluación e incluso la estigmatización. Lo dramático aquí es el desamparo de las poblaciones respecto a instituciones con centros de decisión totalmente extraños y lejanos (compañías transnacionales, Estados potentes) que comandan o amparan esa lógica dominantemente mercantil que las victimiza, aunque tengan conexiones locales que no deben menospreciarse pero tampoco exagerarse. En cuanto a la actual crisis europea, el mal reconocimiento de parados y nuevos pobres adquiere la forma primaria de devaluación, que tiende a derivar en la de invisibilización. En el precario mercado laboral es manifiesta la del reconocimiento inestable y la separación; y en algunos sectores, como los inmigrantes, se hace presente la descalificación - llegando a veces a la estigmatización-. Habría que analizar también qué instituciones densas son las que más están marcando estos procesos negativos: ciertamente la banca, también la gran empresa y las instituciones públicas que se adhieren sumisamente a la lógica de los mercados globales con el riesgo de que lo sustancial de la democracia se diluya, quedando solo sus aspectos superficiales.

Estos brevísimos apuntes dan cuenta de lo enormemente difícil que es enfrentarse a graves mal-reconocimientos institucionalmente sólidos, como los descritos. En la práctica se precisa transformar las instituciones que los vehiculan. Tarea nada fácil para las víctimas. Además, dado que la institución como tal es objetivación de subjetividades, tiende a objetivar a las subjetividades a las que mal reconoce, a sus víctimas —en la depreciación o la invisibilidad-. Estas necesitan entonces resubjetivizaciones, en forma de visibilizaciones apreciativas, que las muestren personas de carne y hueso - porque solo entonces son socialmente víctimas-, con protagonismo emancipador, incluso en el anonimato de la «multitud de víctimas». Retomaré esta cuestión en el último apartado.

\section{RECONOCIMIENTO DE IDENTIDADES Y LÓGICA DEL MERCADO}


El reconocimiento mediado por las instituciones tiene una fuerte relación con la identidad.

1. El sentido primario de reconocer, como indica Ricoeur (2006: 35-36), es el de identificar - asignar una identidad, atribuir una propiedad a alguien o algo-y distinguir — de quienes no son o tienen lo asignado-. La problemática ética aparece cuando esta identificación/distinción supone una evaluación, que es realizada por individuos o, como resalta Renault, por principios normativos institucionalizados —entonces se hace ya problemática ético política-.

El reconocimiento que aquí nos interesa puede remitir: a) a nuestra identidad común como humanos, presente en todo lo que seamos o hagamos; b) a nuestra identidad diferencial - cultural, de género, social, profesional, etc.abierta a su dimensión colectiva y llamada a ser vivida por las personas como identidad dinámica y compleja, la que articula armonizadamente diversas pertenencias identitarias; c) a nuestro hacer y su basamento en nuestra capacidad de iniciativa. Dado que se da una imbricación entre los tres objetivos de reconocimiento, es importante no arrinconar ninguno de ellos en la práctica social.

En correspondencia con esta tríada, el mal reconocimiento puede dirigirse: a) a nuestra identidad compartida de humanos, expresándose como negación de la dignidad de individuos concretos; b) a nuestra identidad colectiva diferenciada, que es menospreciada o estigmatizada; c) al hacer que emana de las capacidades de nuestra identidad, que es considerado o sin suficiente valor, o negativo, o inexistente. Las dos últimas expresiones implican también negación de la dignidad, pero con matices específicos.

Lo que está, pues, en juego, en las expectativas de reconocimiento, es el valor de la identidad. El reconocimiento recibido de los otros es muy relevante para la vivencia de identidades positivas, experimentadas como valor y con un tipo de consistencia que posibilita la crítica de sí. Como subraya Renault (ver su diálogo en Blanchard 2006), la relación positiva consigo mismo está intersubjetivamente constituida, y a su vez es intersubjetivamente vulnerable, por lo que precisa una confirmación intersubjetiva —reconocimiento-, que se convierte así en condición de esa relación positiva consigo. Esto supone que las expectativas de reconocimiento están ancladas en las necesidades del yo, por lo que pueden considerarse cuestión de justicia. Se perciben con más claridad cuando nos hacemos cargo de que en la identidad vivida confluyen las socializaciones que interiorizamos, los reconocimientos que recibimos y el modo como trabajamos ambos aspectos con nuestra iniciativa.

2. Paso ahora a proyectar estas consideraciones al reconocimiento de las víctimas de los mercados, aquí al impacto en su identidad.

Podría decirse que este reconocimiento institucionalizado de los mercados no apunta tanto a la identidad como a la acción. Somete a evaluación nuestra acción productiva y de consumo según el criterio último de capacidad de generación y utilización de riqueza expresable en dinero -o ganancia o beneficio-, sin que como tal incluya el servicio al bien común (desde la teoría 
mercantil, esto vendría en todo caso «por añadidura»). Además, sin prestar atención a las circunstancias favorables o desfavorables en las que podamos estar y que nos exculparían de los fracasos: en parte porque nos toca creárnoslas y en parte porque la «mala suerte», si nos instala en el fracaso, nos acarrea el mal reconocimiento de la invisibilidad. Esto tiene dos derivaciones: ese mal reconocimiento no es juzgado así, pues es considerado justo (o al menos no injusto); y al dañarse el reconocimiento de nuestra capacidad de iniciativa se daña en realidad nuestra identidad, al herirse la relación que mantenemos con la autovaloración de nuestra existencia. ¿Cuánto menosprecio latente induce a asignar a poblaciones enteras que según sus esquemas no muestran ni siquiera el dinamismo mínimo que les posibilitaría no pasar hambre? ¿Cuántos énfasis desmedidos en las responsabilidades personales asigna a quienes se quedan en el paro, a quienes una hipoteca impagable por los cambios en los mercados les bloquea la vida, etc.? ¿Cuánta ceguera hay en estos mercados al no hacerse cargo de todo lo que tienen de freno de la capacidad de iniciativa de las personas, alardeando lo que tienen de estimulación?

Si nos centramos ahora en el mercado laboral, este nos ofrece una identidad mal reconocida, en la forma de identidad menospreciada e inferiorizada, cuando, por someterlo a las leyes de oferta y demanda y del máximo beneficio, e ignorando su orientación primaria a la producción de lo necesario para la sociedad concebida como empresa común —el supuesto normativo del tercer espacio de Honneth-, hace que surjan grandes bolsas de paro que sumergen en la exclusión a los que las sufren; o cuando al amparo de la libertad formal de contratación se generan relaciones salariales denigrantes; o cuando, en el contexto de las actuales flexibilidades y pluralismos de los mercados, se piden tales disponibilidades en las tareas, modos y tiempos del trabajo que dañan la razonable unidad que reclama la identidad positiva, al empujar a la indiferenciación y la dispersión.

Si bien, en principio, el mal reconocimiento de la identidad por los mercados toma la vía indirecta del mal reconocimiento de la acción, también está presente en él el mal reconocimiento dirigido directamente a las identidades diferenciadas. Baste pensar, por ejemplo, en el menor acceso a bienes y servicios y en las mayores dificultades laborales de indígenas, mujeres, inmigrantes, etc. La supuesta referencia de los mercados al individuo «abstracto» queda así desmentida. Es decir, su mal reconocimiento no solo está dañando la identidad compartida de humanidad - la dignidad —, sino también la identidad diferencial que merece respeto. Como reacción, y desde esta perspectiva, la lucha por el reconocimiento se convertirá en lucha frente a las lesiones a la identidad.

\section{LAS LUCHAS POR EL RECONOCIMIENTO Y SU HORIZONTE DE JUSTICIA}

Los diversos considerandos hechos hasta ahora han mostrado cómo el reconocimiento que ofrece el mercado es gravemente victimador. Esta constatación 
nos conduce, evidentemente, a la necesidad de responder a ello a través de luchas por el reconocimiento. Ya se han ido apuntando algunas observaciones sobre ellas, que ahora paso a desarrollar y estructurar.

La lucha por el reconocimiento tiene sentido moral cuando es lucha por la justicia. Ahora bien, la institución del mercado, en cuanto tal, se nos autopresenta no solo como no injusta, sino como la vía más adecuada para que se produzcan bienes que luego se puedan repartir. Habrá que combatir, se dice, los abusos que se producen en ella en forma de corrupciones, engaños y violencias directas, pero es absurdo postular que por ella misma es una violencia estructural, puesto que es la que regula el ejercicio de las libertades en las relaciones de intercambio.

Esta es una justificación ideológica. Para desmontarla se pueden exponer dos líneas argumentales, que aquí únicamente apunto. La primera, ya clásica, modula decisivamente la referencia a los mercados como ejercicio de las libertades señalando que la legitimidad moral se da únicamente en la igualdad de oportunidades sociales, esto es, si se dan equivalentes circunstancias de elección para las personas, lo que supone igualdad de posibilidades de capacitación o empoderamiento. Una sociedad que no cuida esta igualdad contextual material, a través de las correspondientes leyes y políticas públicas, no puede lanzarse a amparar sin más el cruce de iniciativas libres mercantiles, porque expresarán en su conjunto la dominación de los injustamente mejor situados, como de hecho así se está constatando. La segunda línea argumental critica como injusticia no los mercados como tales, sino su imperialismo: pueden tener su justificación en ciertos ámbitos de la vida, pero cuando invaden otros se ilegitiman. Es lo que nos muestra Walzer (1993) en su enfoque sobre la justicia, al señalar cómo hoy la esfera de las mercancías y el dinero, que por sí misma pide que la distribución de bienes se realice según los intercambios libres, está invadiendo otras esferas, como las necesidades básicas de alimentación o salud o educación básica o cobijo digno, que tienen que regirse por el criterio distributivo de a cada uno según sus necesidades. Cuando un bien —como hoy, abrumadoramente, el mercantil dinerario- se hace dominante en una sociedad dada, a lo que se tiende es a monopolizarlo (concentración financieromercantil) y utilizarlo para invadir las otras esferas, con la correspondiente generación de corrupción ${ }^{8}$. Es en esta monopolización e invasión en donde se sitúa la injusticia. Pensando en nuestro ejemplo de las crisis alimentarias: ¿cómo es posible que, políticamente, hayamos dejado la necesidad básica de alimento -el derecho universal a él - al albur de los avatares del mercado? Y pensando en la crisis en Europa: ¿cómo podemos contentarnos políticamente con el hecho de que parezca normal que nos veamos obligados a salvar con dinero público instituciones financieras que se han dedicado al lucro desmedido y han sido agentes activos de la crisis, porque si no las salvamos será todavía

8 Sobre este tema véase también SANDEL (2013) en donde señala que de tener una economía de mercado hemos pasado a ser una sociedad de mercado invasivo. 
peor, confesando así, y dándola por buena, la invasión monetario-mercantil en todas nuestras realidades políticas y sociales? Hay una tercera «argumentación encarnada» para concluir en la injusticia estructural de los mercados, que debería ser decisiva. Si es su propio funcionamiento, como he pretendido mostrar con los casos que expuse, el que motiva que haya millones de personas que no disfrutan de sus derechos básicos a la alimentación, la salud, la educación, la vivienda o el trabajo, esto es, si generan víctimas morales por lo que son, son estas propias víctimas las que se nos muestran como el mejor argumento de su injusticia estructural. Cuando responsables políticos o empresariales - $\mathrm{O}$ académicos, no se olvide- aducen que no queda más remedio que someterse a los mercados, tendrían que ser capaces de seguir aduciéndolo ante la contemplación empática de todas estas víctimas y en la disposición a luchar colaborativamente con ellas para que la victimación desapareciera. Seguro que cambiarían muchas cosas.

Asentado el mal reconocimiento objetivamente injusto de los mercados actuales dominantes, la lucha por el buen reconocimiento, para empezar, tiene que proponerse sintetizar reclamación de redistribución justa y de afirmación de identidad lograda, en sus dimensiones humanamente igualitarias de dignidad y diversidad, desbordando así enfoques que separan distribución de bienes por un lado y reconocimiento de identidades por otro. Reconocer es reconocer lo debido y en ello entra la distribución justa de bienes; distribuir es también distribuir reconocimiento, como un bien que responde a una necesidad básica. Después, las realidades concretas pedirán unos énfasis u otros (ante los millones de hambrientos parece imponérsenos el reconocimiento de la dignidad de cada uno, aunque luego para concretar el acceso y tipo de alimentos también habrá que considerar el reconocimiento de sus identidades colectivas), pero siempre teniendo presente el horizonte completo.

Entrando ya propiamente en la lucha de reconocimiento, una primera consideración se impone: si los mercados son estructuralmente injustos - por algunos de sus rasgos y por su capacidad invasora- el objetivo tiene que ser la transformación estructural. Hay que reconocer que diversas luchas por el reconocimiento persiguen que el mercado «me reconozca bien a mí» con sus pautas actuales. Pero se trata de que nos reconozca bien a todos - horizonte universal de la ética- lo que exige esa transformación. Dicho de otro modo, las luchas por el reconocimiento no deberían ser puramente estratégicas — con el objetivo de mejorar la propia posición - sino que deben ser normativas.

El protagonismo prioritario en las luchas por el reconocimiento tiene que recaer en los mal reconocidos, en las víctimas socialmente organizadas, por supuesto, con los acompañamientos y solidaridades que precisen. Porque es la experiencia de victimación la que, aunque no esté exenta de trampas, mejor revela la injusticia que debe ser suprimida, mejor muestra las personas en las que debe suprimirse y más aliento da para esforzarse en ello. Ahora bien, el mercado tiene una enorme capacidad de paralización de las luchas: hay que enfrentarse a la ideología que lo naturaliza y que se interioriza en nosotros, hay que encontrar recursos que parece que los monopoliza, hay que sustituir 
dinámicas de competición, invasivas de todo, en las que nos ha educado por dinámicas de solidaridad, hay que confrontarse con una realidad financieromercantil sin fronteras desde situaciones geográfico-político-sociales en las que las fronteras existen.

Una primera referencia para afrontar estas dificultades es la del sentimiento. Siempre está presente en las confrontaciones. Pero el enfoque del reconocimiento, tal como se indicó, lo propone expresa y relevantemente. En concreto, el sentimiento de indignación ante la injusticia debe ocupar un lugar clave. Pero también otros, articulándose con él para conducirlo adecuadamente, son importantes ${ }^{9}$. Se trata de cultivarlos colectivamente para que se expresen igualmente de este modo.

Los obstáculos para las transformaciones institucionales exigen también ser creativo-imaginativos en las estrategias de lucha por el reconocimiento frente a la dominación de los mercados. Lo que llamamos movimiento antiglobalización, aunque hoy tenga cierto decaimiento, puede inspirarnos, propositiva y críticamente. También las nuevas movilizaciones ciudadanas (por ejemplo, en España, ante la actual crisis: indignados del 15M, "Rodea el Congreso», plataforma antideshaucios, etc., siempre abiertas a la reflexividad crítica): las alienta la indignación, sintetizan comunicación en red con presencia en las calles fuertemente difundida por los medios de comunicación clásicos, además de las redes; tienen gran flexibilidad en movilidad y liderazgo; se expresan como comunidad de individualidades compartidas más que como convergencia de intereses egoístas; construyen nuevas formas de participación pública. Tienen sus limitaciones y siguen estando precisadas de enlaces — difíciles- con los partidos políticos (con los clásicos o con los que pretendan impulsar desde nuevos parámetros), pero marcan pautas. Además, son contextuales: por ejemplo, para afrontar las crisis alimentarias habrá que buscar otras vías, con fuerte implicación de la dimensión global del movimiento cívico.

La mera descripción de iniciativas como estas muestra ya lo evidente: que la búsqueda de reconocimiento positivo es agonística. Ahora bien, no parece que pueda definirse por la pura lucha. Porque la idea de consenso aparece de dos modos. No tan de arranque y tan omnipresentemente con en Rawls, pero sí en forma importante. En primer lugar, si se quiere que sea una lucha cívica, debe asumir unos supuestos que tengan la suficiente consistencia democrática como para que puedan ser asumidos por todos y a los que se someten las estrategias de lucha. De hecho, movimientos como los citados, al confrontarse contra el imperio de los mercados, especifican también su lucha como profundización en la democracia, purificación y desarrollo de esta, con propuestas que piden debate social, pero que muestran la conexión de lo económico con lo político. En segundo lugar, si se lucha no es para perpetuar la confrontación, sino para llegar a ese consenso que, con conflictividad razonable y no injusta —agonística

9 En EtXeberria (2012) presento una serie de sentimientos en su maduración como virtudes que, aunque no aplicados al tema de este estudio, pueden ser sugerentes para lo que aquí se indica. 
de nivel tenue-, exprese reconocimientos mutuos justos que sostengan las correspondientes conductas cívicas, y así amparen identidades logradas. Esta orientación final al consenso hace que algunas luchas por el reconocimiento, en el caso en el que los mal-reconocimientos hayan sido especialmente duros, sean concebidas también como procesos hacia la reconciliación.

Aunque los mercados han demostrado funcionar tanto en regímenes democráticos como autoritarios e incluso claramente dictatoriales, su halo justificador los conexiona con las libertades civiles: supuestamente, asumirían ese suelo democrático básico. Pero hay que indicar que ni siquiera en estos casos lo asumen de forma consistente, puesto que en su actual funcionamiento global ignoran los derechos sociales. Por eso, teniendo esto presente, así como la intensidad de su dominio, es normal que el agonismo esté llamado a ser fuerte en las actuales luchas contra las dominaciones de los mercados.

Todo buen trabajo de transformación, también el orientado al reconocimiento en su sentido pleno, pide tener como sustrato un buen análisis que incluya tanto la situación socio-económica a la que se enfrentan los mal-reconocidos como la manera en que se sitúan las propias reclamaciones de reconocimiento. Renault (2007: 205) propone este esquema, parcial pero interesante, para realizarlo, que puede ayudar: a) tipología de la negación de reconocimiento; b) distinción entre expectativas implícitas y explícitas de reconocimiento; c) distinción entre luchas de reconocimiento instrumentales y normativas; d) distinción entre luchas agonísticas y consensuales.

Quienes luchan por el reconocimiento no pueden contradecir con sus iniciativas los objetivos que persiguen. Deben mantener una constante alerta crítica sobre sí mismos. Esto puede pedir lo siguiente. En primer lugar, ser honestos con la motivación de las luchas, esto es, inspirarlas en mal-reconocimientos que se vivencien como sufrimientos que tengan causas sociales, aquí, ocasionadas por los mercados, que sean injustas; cuando hay oscuridad en esto, el discernimiento, a través de debates sociales francos, se impone. En segundo lugar, es importante purificar el objetivo de reconocimiento buscado: se nos puede colar el anhelo de reconocimiento puramente mercantil. En tercer lugar, en cuanto a los medios utilizados, si lo que buscamos es buen reconocimiento, no podemos acudir a medios que impliquen mal-reconocimientos de otros; se impone a este respecto la inspiración en la no violencia, la que no daña el reconocimiento como sujeto de dignidad ni siquiera del opresor.

El horizonte de esta lucha por el reconocimiento, impactando las instituciones sociales y políticas, reconfigura el contenido de la justicia. Esta pasa a medirse por «la capacidad de asegurar las condiciones de reconocimiento mutuo en las que la formación de la identidad personal y, en consecuencia, la autorrealización individual puede desarrollarse de manera adecuada» (Honneth, en Fraser y Honneth, 2006: 136). Personalmente, revisaría — contra la opinión de Honneth - y completaría la afirmación incluyendo las identidades colectivas. Lo que aquí quiero subrayar, en cualquier caso, es que la justicia se muestra ahora como garantía de las condiciones sociales del buen funcionamiento del reconocer/reconocerse/ser reconocido en todos. Esta es su expresión formal. 
La material tiene que ver con las condiciones precisas con las que se acaba con los mal-reconocimientos existentes, como los implicados en los mercados.

De todas maneras, cuando contemplamos no solo la superación de los reconocimientos falseados, sino también las víctimas que los han sufrido, esta mera mirada al futuro no es suficiente. La víctima lo ha sido a consecuencia de una historia de violencia, y esa historia debe ser retomada: como fuente de verdad para la justicia; como referencia de memoria para la identidad y el futuro; como posibilidad de volver a ella, por parte de víctimas y victimarios, en formas tales que, sin menoscabar en nada los derechos de la víctima, se pueda reconfigurar el sentido de lo que pasó y abrir a la reconciliación —asimétrica, porque el camino que tiene que recorrer la víctima y el que tiene que recorrer el victimario no son los mismos-. Los teóricos del reconocimiento no han prestado suficiente atención a esta cuestión. Es fácilmente planteable, aunque difícil de realizar, cuando las violencias son directas. Pero vuelve a ser difícil incluso en sus planteamientos cuando son estructurales, como es el caso de las violencias de los mercados ${ }^{10}$ : por la despersonalización del victimario en la estructura, por la multitud anónima de las víctimas, porque el relato no se deja construir con la facilidad de los acontecimientos en los que la intersubjetividad es manifiesta. Pero, a pesar de ello, con la ayuda de los historiadores cuando se precise, hay que alentar la construcción de la historia del mal reconocimiento, en este caso por los mercados, para que podamos acoger a fondo a sus víctimas en las narraciones que las han constituido como tales y hacernos cargo de las dinámicas de mal que les acontecieron y de los sujetos personales e institucionales que se las causaron, así como acoger también sus esfuerzos por enfrentarse a las violencias sufridas. ¿Podremos, por ejemplo, hacer una historia de las comunidades humanas afectadas gravemente por el hambre evitable, que nos llegue como nos llegan los relatos de víctimas de nuestro país? ¿Una historia que vaya al corazón de lo que pasó?

Para concluir el recorrido hecho, permítaseme volver a la vieja idea hegeliana de que, en el reconocimiento intersubjetivo, no solo el modo como nos reconocemos sino también nuestras identidades, son interdependientes. Las víctimas que logran que triunfe el buen reconocimiento, aquí en los mercados, transforman la identidad de estos, transforman la identidad de las personas que se remiten a ellos. Y lo hacen en la línea de mayor humanidad porque, como indica Honneth (1996: 140), todo buen reconocimiento implica «restricción de egocentrismo», en la medida en que supone apertura a los propósitos, necesidades e identidades de los demás. Soy consciente de que el referente del reconocimiento no debe ser el único para afrontar las grandes victimaciones, que hay que articularlo con otros, pero espero haber mostrado que es un referente clave.

10 Expongo con detalle esta cuestión, aplicándola a las víctimas del terrorismo, en ETXEBERRIA (2012a). Planteo el tema de la memoria abierto a otras víctimas, apuntando ya la dificultad que aquí indico, en EtXEBERRia (2010). 


\section{REFERENCIAS BIBLIOGRÁFICAS}

Alonso, M. (2013), «Las garras del poder medio». Claves, 229, 48-59.

Blanchard, M. et al. (2006), «L'experience de l'injustice». Les ateliers de l'éthique, 2, 128-133.

CaIllé, A. (2004), «Présentation». Revue du MAUSS, 23, 5-28.

DuRANTY, J.-P. (2005), «Les horizons marxistes de l'éthique de la reconnaissance». Actuel Marx 38, 159-178.

EtXeberRia, X. (2010), «Víctimas y memoria». Papeles de relaciones ecosociales y cambio global, 109, 57-66.

ETXEBERRIA, X. (2012a), Ética del reconocimiento y víctimas del terrorismo. Isegoría, 46, 215-232.

ETXEBERria, X. (2012b), Virtudes para convivir. Madrid, PPC.

Fraser, N. y Honneth, A. (2006), ¿Redistribución o reconocimiento? Madrid, Morata.

Galtung, J. (1985), Sobre la paz. Barcelona, Fontamara.

Hegel, G. W. F. (2009), Fenomenología del espíritu. Valencia, Pre-textos.

Honneth, A. (1996), «Reconocimiento y obligaciones morales». Revista Internacional de Filosofía Política, 8, 5-17.

Honneth, A. (1997), La lucha por el reconocimiento: por una gramática moral de los conflictos sociales. Barcelona, Crítica.

Honneth, A. (2006), «El reconocimiento como ideología». Isegoría, 35, 129-150.

Honneth, A. (2010), Reconocimiento y menosprecio. Sobre la fundamentación normativa de una teoría social. Madrid, Katz editores.

JAESChKE, W. (2009), "Il riconoscimento come principio dell'ordinamento statale e interstatale». Archivio di Filosofia, 2-3, 189-198.

Maza, L. M. de la. (2009), «El sentido del reconocimiento en Hegel». Revista latinoamericana de filosofía, 35, 227-251.

Navarro, V.; Torres, J. y Garzon, A. (2012), Hay alternativas. Madrid, Sequitur.

OXfam Internacional (2013), La trampa de la deuda. www.intermonoxfam.org (recuperado el 25 de septiembre de 2012)

Pierini, T. (2009), «Riconoscimento, riconciliazione, conoscenza. Sulla sequenza logica del riconoscimento nella Phänomenologie des Geistes». Archivio di Filosofia, 2-3, 21-29.

Renault, E. (2000), Mépris social. Ethique et politique de la reconnaissance. Bègles, du Passant.

Renault, E. (2004), L'expérience de l'injustice. Reconnaissance et clinique de l'injustice. París, La Découverte.

RENAULT, E. (2004b), «Reconnaissance, institutions, injustice». Revue del MAUSS, 23 (1), 15-35.

Renault, E. (2007), «What is the Use of the Notion of the Struggle of Recognition?» Revista de Ciencia Politica, 2, 195-205.

Ricoeur, P., Caminos de reconocimiento. México, FCE.

SANDEL, M., Lo que el dinero no puede comprar. Barcelona, Debate.

TAYLOR, C. (1996), «Identidad y reconocimiento». Revista Internacional de Filosofía Política, 7, 10-19.

TAYlor, C. (1997), «La política del reconocimiento», en: Charles TAYLor, Argumentos filosóficos, Barcelona, Paidós, 293-334.

Walzer, M. (1993), Las esferas de la justicia. México, FCE.

Universidad de Deusto

Xabier EtXEBERria

xetxemau@deusto.es

[Artículo aprobado para publicación en noviembre de 2014] 
